Discussion Paper No. 17-007

\title{
Digital Design Protection in Europe: Law, Trends, and Emerging Issues
}

Rainer Filitz, Joachim Henkel, and Jörg Ohnemus

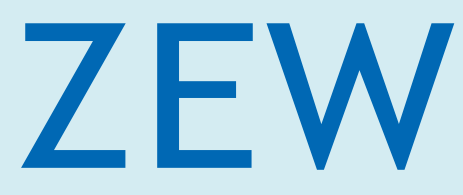

Zentrum für Europäische Wirtschaftsforschung $\mathrm{GmbH}$ Centre for European Economic Research 
Discussion Paper No. 17-007

\section{Digital Design Protection in Europe: Law, Trends, and Emerging Issues}

Rainer Filitz, Joachim Henkel, and Jörg Ohnemus

Download this ZEW Discussion Paper from our ftp server:

http://ftp.zew.de/pub/zew-docs/dp/dp17007.pdf

Die Discussion Papers dienen einer möglichst schnellen Verbreitung von neueren Forschungsarbeiten des ZEW. Die Beiträge liegen in alleiniger Verantwortung der Autoren und stellen nicht notwendigerweise die Meinung des ZEW dar.

Discussion Papers are intended to make results of ZEW research promptly available to other economists in order to encourage discussion and suggestions for revisions. The authors are solely responsible for the contents which do not necessarily represent the opinion of the ZEW. 


\title{
Digital Design Protection in Europe: Law, Trends, and Emerging Issues
}

\author{
Rainer Filitz $^{\text {a }}$, Joachim Henkel ${ }^{\text {a,b }}$, Jörg Ohnemus ${ }^{\text {c }}$ \\ a TUM School of Management, Technische Universität München; Arcisstr. 21, 80333 Munich, Germany, \\ filitz@wi.tum.de,henkel@wi.tum.de \\ ${ }^{\mathrm{b}}$ Center for Economic Policy Research (CEPR), London, United Kingdom \\ ${ }^{\mathrm{c}}$ Centre for European Economic Research; L 7, 1, 68161 Mannheim, Germany, ohnemus@zew.de
}

January 2017

\begin{abstract}
Digital designs - that is, designs for display on electronic screens - have recently burst onto the intellectual property (IP) stage. While in the U.S. a smattering of legal studies have recently addressed the question of digital design as a copyright-, trademark- and patenteligible subject matter, a European perspective is still lacking in the literature. This study provides an overview of basic legal background to the protection of digital designs in Europe, explores firms' actual digital design protection behaviors, and highlights some important practical and doctrinal issues that warrant further study.
\end{abstract}

Keywords: digital designs, intellectual property, RCD, interviews, survey

JEL Classification: K11, O31, O34

Acknowledgments: The authors gratefully acknowledge the funding from the European Community’s Seventh Framework Programme under grant agreement CRE8TV.EU-320203 that has enabled us to undertake this research. 


\section{Introduction}

Digital designs - that is, designs for display on electronic screens - have recently burst onto the intellectual property (IP) stage. Graphical user interfaces (GUIs) and associated visual elements, such as icons, dialog boxes and transitional animations, are among the fastest growing segments of U.S. design patent and European registered design filings (Du Mont and Janis, 2014; Filitz et al., 2015), and firms are getting under way to spend considerable resources contesting their digital design rights in court. Most prominently, as part of Apple's nearly billion dollar verdict against Samsung in 2012, a U.S. jury found that Samsung's smartphone home screen design, specifically its rows of buttons with rounded corners, had infringed one of Apple's digital design patents. In the aftermath of this headline-grabbing case, Google, Facebook, and others have raised the concern that a company could lose its entire profits on a complex multi-component product due to damage payments for infringing just a single protected icon. ${ }^{1}$ A similar legal dispute between Apple and Samsung in Europe, which involved a registered community design (RCD) for the iPhone's GUI, was settled in August 2014.

Firms' increasing demand for legal protection of digital designs does not come as a surprise. Devices with electronic screen displays are commonplace nowadays: computers, smartphones, tablets, or household appliances - digital designs are often critical to the overall appearance and usability of these products and thus serve as important differentiators in crowded marketplaces. In fact, the share of industrial designs implemented in digital form is expected to exceed that for traditional physical designs by 2018 (Gutiérrez, 2012). This "virtual migration” from three-dimensional physical design to digital design on twodimensional computer screens poses challenges to both, policy makers in charge of adapting the legal IP framework to the requirements of digital designs, and firms seeking to protect this increasingly important type of intellectual property.

While in the U.S. a smattering of legal studies have recently addressed the question of digital design as a copyright-, trademark- and patent-eligible subject matter, and provided a first glimpse into the empirics of firms' digital design protection behaviors (Du Mont and Janis, 2014; Risch, 2014; Stigler, 2014), a European perspective is still lacking in the literature (for an early exception, see Kur, 2003). The objective of this study is therefore threefold: (i) to provide an overview of basic legal background to the protection of digital

\footnotetext{
${ }^{1}$ See http://www.fosspatents.com/2015/07/google-facebook-hp-others-warn-company.html (last accessed: 31 July 2015).
} 
designs in Europe, (ii) to explore firms' actual digital design protection behaviors, and (iii) to highlight some important practical and doctrinal issues that warrant further study.

We begin in Chapter 2 by outlining the pros and cons of different forms of intellectual property rights (IPRs) with regard to their protection of digital designs, concluding that industrial design rights, such as the popular RCDs, generally provide the best fit. In Chapter 3, we then exploit statistical and interview data to examine firms' use of RCDs for digital designs in greater detail. This reveals some major obstacles to the effective protection of digital designs through registration, so that the system is currently attractive only for a small number of producers of highly valuable digital designs. Chapter 4 presents results of a survey among German firms in information-related industries, focusing on the use of various legal means to protect digital designs and on potential reasons speaking against the use of digital design rights. Chapter 5 concludes.

\section{Legal mechanisms for the protection of digital designs in Europe}

There are three main legal instruments available to owners seeking to protect their digital designs in Europe: copyright, trademarks and industrial design rights. ${ }^{2}$ Although these three legal regimes overlap, each entails a unique set of standards and scope of protection that affect its eligibility with regard to designs in the virtual realm. As outlined below, industrial design protection, and registered design rights in particular, are a relatively good fit for digital designs compared to copyright and trademark protection.

\subsection{Copyright protection}

Digital designs may qualify for protection under national copyright laws to the extent that they are an author's own intellectual creation and reflect a certain degree of creativity. Copyright protection arises automatically once the work has been expressed in perceptible form (i.e., mere thoughts and ideas are excluded from protection) and generally lasts for the lifetime of the author plus 70 years. Current judicial practice holds that copyright protection of the underlying software program does not extend to the digital designs generated by that software (and vice versa), meaning that visual appearance and software code need to be

\footnotetext{
${ }^{2}$ Country-specific laws such as unfair competition law in Germany, or the law of "passing off” in the UK may also be relevant, but play a rather marginal role in practice and thus are not considered further in this paper.
} 
assessed separately as copyrightable subject matter (e.g., CJEU C-393/09 BSA vs. Ministry of Culture).

While some aspects of national copyright laws have been harmonized through EU directives and international treaties (such as the Berne Convention), differences still exist across member states, especially with regard to the originality threshold required for protection. German copyright law, for example, has traditionally applied a rather elevated originality standard for works of applied art. As most digital designs can be classified as "applied” rather than "purposeless” (i.e., museum style) art, copyright protection has remained severely limited. In a recent decision (I-ZR-143/2013 Birthday Train) the German Federal Supreme Court set however a new precedent by lowering the originality threshold for applied art to the level of that for purposeless art, thereby following the practice of most other European countries (Gausling, 2014).

But even if copyright protection is principally available for a sizable portion of digital designs, it is likely to be thin, because the visual appearance of GUIs, icons and the like is often heavily influenced by functional considerations and therefore leaves little room for elements of personal expression and creativity (cf. Microsoft's recycling bin icon or Apple's slide-to-unlock design). Moreover, due to the lack of legal harmonization of copyright laws across Europe, cross-border enforcement is cumbersome, costly and its outcome often unpredictable - claims against alleged infringers need to be litigated in each relevant national court according to the rules applicable in that particular jurisdiction. This combined with the difficulty of tracking authorship and proving copying in case of infringement (copyright does not provide protection against independent creations of similar works) currently makes copyright a relatively unattractive option for the protection of digital designs in Europe.

\subsection{Trademark protection}

If digital designs are capable of distinguishing products or services from a particular source from those of others, they may be eligible for protection under the trademark regime. Examples include easily identifiable GUI elements (e.g., Facebook’s “like” button), static or dynamic representations of logos in digital environments (e.g., the in- and out-fading Microsoft flag on the Windows 7 boot screen), as well as source-indicating colors (e.g., Tiffany’s homepage design in robin egg blue). Trademark rights are usually conferred upon registration and office examination in relation to a limited number of product and service 
categories for which protection is sought. ${ }^{3}$ Dependent on the geographic scope, applications may be submitted to individual countries' national IP offices, or to the Office for Harmonization in the Internal Market (OHIM) which administrates community trademarks (CTMs) with unitary effect throughout the EU. National laws implement EU directives, such that the requirements for obtaining trademark protection through registration are substantially the same across member states and for the EU as a whole.

As most digital designs are devoid of any source-indicating function, trademark law offers protection only for a very narrow group of highly recognizable digital designs the development of which usually requires substantial marketing investments. However, once trademark protection is established and as long as the good or service is used in commerce, it may be renewed indefinitely, for ten years at a time.

Increasingly important, but as yet unanswered questions concern the enforcement of trademark protection for designs that make the transition from physical to digital, and vice versa. For example, it is arguably more difficult to demonstrate risk of consumer confusion one of the tests applied in trademark infringement - if a trademark for a physical design is not infringed in the real world but by a digital model in a virtual environment, such as a video game or Second Life. ${ }^{4}$ In particular, are the product and service categories defining the scope of trademark protection the same before and after transition? And moreover, given that the boundaries between private and commercial sphere become increasingly blurred in such contexts, how to prove use in the course of trade on part of the alleged infringer (another requirement for trademark enforceability)? For example, when digital designs, by means of 3D printing, are converted into physical products for private use, trademarks are generally ineffective.

Industrial design protection, which we discuss next, does not encounter these problems, as it provides protection independent of specific product and service categories, and entitles its holder to prevent any third party from reproducing the design, even in non-commercial contexts.

\subsection{Industrial design rights}

Any digital design that is new, that is, not identical to prior designs disclosed, and that has an individual character such that an "informed user" would perceive the design as being

\footnotetext{
${ }^{3}$ In addition, some EU countries provide protection for unregistered trademarks established through actual use in the marketplace, such as the UK under the common law tort of "passing off."

${ }^{4}$ Note that platforms for selling unauthorized computer models of real world products are thriving - see, for example, www.3dexport.com and www.turbosquid.com.
} 
different from prior designs may receive protection as an industrial design right. This eligibility standard is arguably low compared to those for copyright and trademark protection - the design just has to be sufficiently different, neither must it bear an imprint of personal expression and creativity nor serve as an indication of a particular commercial source.

As for trademarks, the landscape of design protection has been widely harmonized across the EU. All member states are mandated to provide harmonized protection of designs by means of national registration procedures, and moreover there exist two EU-wide design rights: the registered community design (RCD), which can be filed with OHIM, and the unregistered community design (UCD), which affords automatic protection against copying for three years from the date of disclosure in the EU. ${ }^{5}$ While registered design rights and UCDs share the same requirements and scope of protection, registration provides protection for up to 25 years (subject to payment of renewal fees every five years) and confers the proprietor the exclusive right to use the design, that is, there is no need to prove copying in case of infringement. ${ }^{6}$ An important feature of RCDs (and indeed registration with most individual member states) is that the substantive requirements for protection - "novelty" and “individual character" - are not examined prior to registration. Rather, registered designs are assumed to be valid unless and until successfully challenged.

From a legal standpoint, digital designs are well accommodated in European design law. First, according to Article 1(a) of the Design Directive (98/71/EC), “design” refers to the appearance of the whole or a part of a product. Accordingly, not only the overall look of an electronic screen display (e.g., the entire GUI) may qualify for protection, but also individual elements thereof (e.g., icons, buttons, and dialog boxes). This offers creators some flexibility with regard to the protection of the truly distinctive features of their digital designs and provides opportunities for creating layers of registered design protection.

Second, the notion of a "product," as specified in Article 1(b) of the Design Directive, is generously broad and - importantly in our context - explicitly includes graphic symbols and typographic typefaces. There is no requirement that the design must be applied to an article of manufacture, and if it is, the article of manufacture (e.g., the computer on which the GUI is displayed) does not have to be included as part of the design claim. Indeed, as stated above,

\footnotetext{
${ }^{5}$ Some EU countries, including the UK, also recognize national unregistered design rights, the implementation of which is left to the member states' discretion.

${ }^{6}$ Another weakness of UCDs is that holders, when defending their rights in court, need to provide proof of the date and the place of the design's first disclosure. Attesting that disclosure has taken place within the territory of the EU can be particularly challenging in the context of digital designs, as these are often published online, and therefore the location of disclosure could be defined in different ways (e.g., the physical location of (i) the designer, (ii) the server on which the website is hosted, or (iii) sale of the products and services). Case law concerning this issue is yet to be established.
} 
design rights owners may claim protection against any reproduction that creates the same overall visual impression, irrespective of the similarity of products for which the design is used (i.e., a plush toy resembling the look of a video game character may infringe upon the rights of the latter, and vice versa). By reciprocity, prior art from all sectors is principally applicable when considering a design right's validity (EWCA 358/2008 Green Lane vs. $P M C)$.

Finally, the functionality doctrine, which prevents technical features embedded in designs from being protected by other means than patent law, is relatively lax in the context of (un)registered design rights in Europe (Du Mont and Janis, 2012; Schickl, 2013). Specifically, Article 7 of the Design Directive sets forth that design features are excluded from protection if they are solely dictated by the product's technical function. Thus, if the same technical effect may be achieved with any different form - as will be the case for most digital designs ${ }^{7}-$ the exclusion criterion does not apply.

\section{Exploring firms' use of RCDs for digital designs}

In this section, we examine firms' use of RCDs for digital designs in greater detail. We focus on RCDs because the preceding legal analysis has shown that registered designs provide several unique advantages over other types of IPRs when it comes to the protection of designs in the virtual realm. Moreover, RCDs have generally emerged as an important method for design protection in the EU, as is apparent from the extent of firms' registration and enforcement activities (Filitz et al., 2015).

We begin our exploration with a descriptive analysis of data from the OHIM register, to identify trends and peculiarities in filing activities for screen displays, graphical user interfaces, and icons (these are summarized in Class 14.04). To illuminate and complement this statistical data, we then report some qualitative evidence on how and why RCDs for digital designs are actually used in practice, and here we discuss the findings of interviews with IP experts of both European law firms and companies that produce digital designs.

\footnotetext{
${ }^{7}$ For example, hardware constraints, such as screen resolution and touch-screen operability, may necessitate particular digital design features. For a detailed discussion, see Stigler (2014).
} 


\subsection{Patterns of RCD use for digital designs}

Over the decade since 2004, when registration in Class 14.04 became first available, the number of digital designs submitted to OHIM has grown markedly, from less than 500 in 2004 to more than 2,500 in 2013 (see Figure 1). As such, Class 14.04 stands out as one of the most dynamic product categories in terms of annual growth in applications (cf. Filitz et al., 2015, p. 1197). In total, 12,923 digital designs were registered until the end of 2013, including 412 (27\%) single and 1,090 (73\%) multiple applications. The latter, which allow simultaneous filing of multiple independent designs in the same product category at a discounted rate, are particularly prevalent in Class 14.04, with the average number of digital designs submitted in applications (8.6) being more than twice as large as the corresponding number for all RCD registrations (3.8).

Figure 1: RCD applications in Class 14.04, 2004-2013.

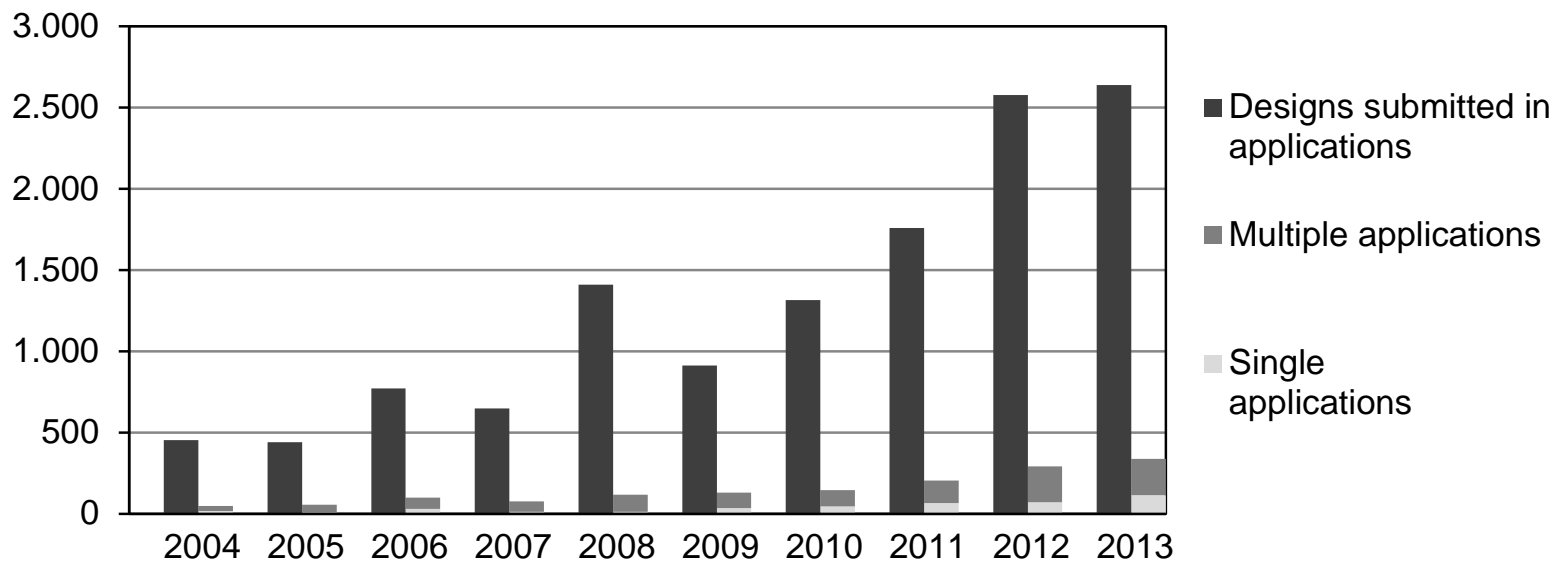

Source: OHIM database

Of the designs registered in Class 14.04, the largest share (36\%) is designated as "graphical user interfaces,” while “icons” (27\%) and "display screens” (23\%) also feature prominently. “Animated designs” (5\%), “websites” (3\%), and the residual category (5\%) account for considerably smaller portions. Applicants based in the U.S. have been most active in filing RCDs for digital designs; in fact, they are responsible for about every third registration in Class 14.04. Together with applicants from South Korea and Japan, these "high-tech" countries account for nearly 50\% of all digital design filings. The most prolific EU-users are Germany and the UK with shares of $19 \%$ and, respectively, $6 \%$ of total registrations. As shown next, the distribution of filing activities across countries becomes 
more understandable when considering firm-level application numbers after consolidating applicant names.

Table 1 ranks the top 15 applicants of RCDs in Class 14.04 by total registrations between 2004 and 2013, and it is immediately clear that the registered designs in this field are predominately owned by a small number of large software, consumer electronics and telecom companies. Perhaps unsurprisingly, Microsoft heads this list with 2,050 registrations, followed by Apple and Samsung with about half of that number each. The three top filers, which also head the corresponding list for U.S. digital design patents (Du Mont and Janis, 2014), register on a fairly regular basis, while most other top applicants file much more occasionally, typically many designs at the same time. Some firms clearly focus on covering the appearance of their online presence in digital design registrations (e.g., Yoox, King.com, Visa Europe), others put more emphasis on the GUIs of their electronic devices (e.g., Daimler, Siedle, Siemens).

Table 1: Top applicants of RCDs in Class 14.04.

\begin{tabular}{|c|c|c|c|c|c|c|c|c|c|c|c|c|c|}
\hline & Applicant & 2004 & 2005 & 2006 & 2007 & 2008 & 2009 & 2010 & 2011 & 2012 & 2013 & Total & $\begin{array}{c}\text { Designs per } \\
\text { appl. (Ø) }\end{array}$ \\
\hline 1 & MICROSOFT & 29 & 208 & 162 & 110 & 118 & 194 & 124 & 545 & 331 & 229 & 2,050 & 13 \\
\hline 2 & APPLE & & & & 219 & 412 & 26 & 111 & 82 & 196 & 30 & 1,076 & 30 \\
\hline 3 & SAMSUNG & & 20 & 33 & 9 & 10 & 16 & 21 & 62 & 301 & 526 & 998 & 10 \\
\hline 4 & $\begin{array}{l}\text { DEUTSCHE } \\
\text { TELEKOM }\end{array}$ & & & & & 237 & 94 & 10 & & 55 & 32 & 428 & 16 \\
\hline 5 & SONY & 1 & 11 & 5 & & & 6 & 28 & 213 & 112 & 5 & 381 & 20 \\
\hline 6 & YOOX & & & & & & 74 & 226 & & 21 & & 321 & 40 \\
\hline 7 & BLACKBERRY & & & & & & & 3 & 9 & 121 & 77 & 210 & 3 \\
\hline 8 & DAIMLER & 51 & & 92 & 11 & & & & 8 & & & 162 & 20 \\
\hline 9 & UIQ TECHNOLOGY & & & 161 & & & & & & & & 161 & 161 \\
\hline 10 & KING.COM & & & & & & & & & & 152 & 152 & 51 \\
\hline 11 & VISA EUROPE & & & & & & & & & & 134 & 134 & 134 \\
\hline 12 & DELTA DORE & & & & & & & & & 125 & & 125 & 42 \\
\hline 13 & ADP GAUSELMANN & & & & & & & 111 & & & & 111 & 111 \\
\hline 14 & SIEDLE & & & & & & & 10 & 35 & & 48 & 93 & 31 \\
\hline 15 & SIEMENS & 31 & & & 16 & & 2 & 16 & & 22 & & 87 & 15 \\
\hline
\end{tabular}

Source: OHIM database

Several questions arise from this firm-level data. In particular, why do just a few large enterprises dominate the digital design registration landscape; and what are the key obstacles to registration, or reasons for lacking motivation, for others? Given the ubiquity of digital 
designs in modern markets, the generally low entry barriers for this type of intellectual property, as well as the legal advantages of RCDs in facilitating exclusive use over them, a more diverse filing activity among different types of firms and industries might have been expected. Furthermore, as RCD applications are not examined by office personnel, how confident are applicants about the validity and scope of protection of their digital design registrations (note that these constitute relatively new legal territory for most firms)? The qualitative evidence presented below provides some preliminary answers to these questions, and intends to develop a more detailed general understanding of firms' behaviors with regard to RCDs for digital designs.

\subsection{Expert interviews on the use of RCDs for digital designs}

\subsubsection{Sample and method}

Due to the specific and nascent nature of the topic, information was sought from key informants who were knowledgeable about digital design protection and who participated in strategic decisions regarding this form of IP protection within their organizations. Through a detailed analysis of registration, invalidation and litigation data, six legal experts could be identified that had first-hand experience with digital design rights and were willing to participate in the interview study. Apart from one representative at OHIM, these included five partners of European law firms, advising, amongst others, several heavy users of digital design registrations such as Apple, Samsung, and Deutsche Telekom (see Table 2). To put the specialists' statements into perspective, our sample furthermore includes a group of general experts for design-related IPRs - both company representatives of German firms and their legal advisors - who had at least touched on the issue of digital design protection. 
Table 2: List of interviews

\begin{tabular}{|c|c|c|c|}
\hline & Company (country) & Position & Selected clients \\
\hline \multirow{6}{*}{$\begin{array}{l}\text { Experts on } \\
\text { digital design } \\
\text { protection }\end{array}$} & Bardehle Pagenberg (DE) & Partner & Apple, Software AG \\
\hline & Hogan Lovells (ES) & Partner & $\begin{array}{l}\text { Deutsche Telekom, Panasonic, } \\
\text { BlackBerry }\end{array}$ \\
\hline & Marks \& Clerk (UK) & Partner & Samsung, Facebook, Smart Technologies \\
\hline & OHIM (ES) & Head of Invalidity Div. & \\
\hline & RGC Jenkins (UK) & Partner & Casio, Orange UK \\
\hline & Simmons \& Simmons (UK) & Partner & Samsung, Trimble Navigation \\
\hline \multirow{7}{*}{$\begin{array}{l}\text { General design } \\
\text { protection } \\
\text { experts }\end{array}$} & Bird \& Bird (DE) & Counsel & \\
\hline & BMW (DE) & Head of TMs and Designs & \\
\hline & Kuhnen \& Wacker (DE) & Partner & Toyota, Denso, Yokohama \\
\hline & Robert Bosch (DE) & Vice President IPR Dep. & \\
\hline & Daimler (DE) & Head of TMs and Designs & \\
\hline & Prinz \& Partner (DE) & Partner & Volvo \\
\hline & Wbetal (DE) & Partner, Partner & Toyota \\
\hline
\end{tabular}

A total of 13 interviews were conducted according to a semi-structured approach which allowed us to pursue a consistent line of inquiry, while leaving flexibility to address promising topics and themes as these arose during conversations (Rubin and Rubin, 2005). The interviews with the digital design protection specialists lasted on average 81 minutes, those with the general design protection experts 71 minutes. Combined, 16 hours of interviews were recorded, transcribed, and coded. Throughout the fieldwork, we engaged in an iterative process of data collection, data condensation, and conclusion drawing to guide further data collection (Miles and Huberman, 1994).

\subsubsection{Results}

As is apparent from the firm-level application numbers in Table 1, there is significant variation in firms' propensities to register digital designs. Based on the interviews we were able to better understand these differences. Specifically, it turned out that there are essentially two types of RCD users for digital designs. The first group includes some of the heaviest applicants in Class 14.04, for which digital design registrations play an increasingly important role in their IPR portfolios. One top applicant's IP lawyer summarized the advantages of RCDs for protecting digital designs as follows: 
No copyright, because it's not harmonized; trademarks - difficult to be obtained, and the scope is limited to the class and goods you have registered; so it's about design rights, basically. And it's not about unregistered design rights, because these are only against copying and have three years' term of protection only. So the answer is very clear.

Despite a lack of relevant case law, informants representing the few heavy registrants felt rather confident about the validity and scope of protection of their digital design registrations. In fact, even the possibility of legal action against infringement of RCDs was expected to deter imitators of digital designs to some extent.

The majority of firms belonged however to the second group of more hesitant users. While generally recognizing the need for digital design protection and appreciating the advantages of RCDs in this regard, most companies and their legal advisors were reluctant to make regular and extensive use of digital design registrations because of the perceived uncertainty surrounding their validity and enforceability. As a company representative concerning the automotive industry confessed:

We have started a few trial balloons. [...] But in the end Apple and Samsung have to tell us whether this makes sense.

Factors that loom large in explaining this inter-group heterogeneity are the significant legal expertise and financial resources required to establish thorough protection for digital designs through registration. The principal test for RCD infringement is whether the allegedly infringing design generates the same overall impression as the design submitted as part of the application. Registrants therefore need to find a way to adequately represent the specific parts of the design that are likely to be imitated, while at the same time conveying a look general enough to secure a proper scope of protection. This is particularly challenging in the context of complex graphic content of which GUIs, websites, or in-game environments are prominent examples. In practice, it means that to ensure sufficient protection companies often have to register dozens, sometimes hundreds, of variations of an overall digital design at the same time, each covering and emphasizing different elements, arrangements, levels of specificity, et cetera. To some extent, this behavior is reflected in the prevalence of multiple applications in Class 14.04. The lawyers' advice was clear: 
The more registrations you file, the better chances you have of getting infringers who are coming after or trying to copy what you do.

We talk about families. It's the core design [registration] plus variations.

Although the RCD system offers a discount for mass applications, ${ }^{8}$ the fees payable to OHIM can still add up, and - together with the costs of planning and preparing mass applications - often make such multiple filing strategies prohibitively expensive, especially for small firms.

Another barrier to the registration of digital designs was ascribed to their frequently animated nature. Interviewees criticized that many digital designs that feature transient or moving elements - while constituting eligible subject matter - could not be adequately captured by a maximum of seven static views which are permitted in the "paper logic" registration system. ${ }^{9}$ Instead of the current practice of delineating animated content in an application as multiple snapshots shown in a sequence, it was therefore suggested to open the design registration system for submission of short videos and GIF files. ${ }^{10}$ At the same time, interviewees pointed to the need to carefully coordinate any modernization of design protection schemes across major jurisdictions, to avoid additional complexity in international filing strategies.

A final issue concerned the enforceability of RCDs for digital designs, in particular through border seizure. It appeared from the interviews that RCDs were primarily used as tools to combat counterfeiting and hence were often registered with the customs to prevent copies from entering the European market. However, the effectiveness of border seizure was severely questioned in the context of digital design registrations: Since electronic devices are generally imported “offline” (i.e., the software and electronic screen are not active), there is (i) no prima facie indication of any infringing digital design, so that the counterfeit good is difficult to identify, and (ii) uncertainty about whether importing a computer-stored but nonactive digital design constitutes an infringing act at all.

Taken together, although the unexamined RCD system is meant to be simple and inexpensive to use, we found strong evidence that, in most real cases, significant know-how

\footnotetext{
${ }^{8}$ The office fees for protecting a single design for five years are $350 €$; the $2^{\text {nd }}$ to $10^{\text {th }}$ design each cost $175 €$; while each further registration (up to a maximum of 99 designs) costs $80 €$.

9 This limit stems from the minimum number of views required for a comprehensive two-dimensional representation of a three-dimensional object: one view from each side, one each from the top and the bottom, and one in perspective.

${ }^{10}$ In fact, corresponding plans are underway at the World Intellectual Property Organization (WIPO). See http://www.wipo.int/edocs/mdocs/hague/en/h_ld_wg_2/h_ld_wg_2_3.doc (last accessed: 31 July 2015).
} 
and financial expenditures are required to establish thorough protection for digital designs. When considering whether or not to take out a digital design registration, applicants should ultimately consider the cost of obtaining protection, relative to both the value of the design for which protection is sought and the effectiveness of the protection provided. Currently, the RCD system appears to be attractive only to a smattering of owners of highly valuable digital designs that moreover have the financial resources to seek advice from the most experienced lawyers in the field (e.g., Microsoft, Apple, Samsung, and Deutsche Telekom). While the legitimacy and effectiveness of protection through digital design registrations will likely be more firmly established in future case law, additional measures could be undertaken to enhance the system's attractiveness for a broader and more diverse set of firms. For example, clear guidelines on how to efficiently depict complex GUIs and websites in (multiple) applications, and the allowance of animated forms of visual representation would not only help to cut down the number of registrations required per design but also to maintain the registry’s transparency.

\section{Exploratory survey among German firms in the ICT industry}

Complementing the quantitative analysis of RCD registrations of digital designs and the qualitative evidence from our interviews, we now present results of a quantitative survey addressing how, and why (or why not) firms use digital design rights.

\subsection{Sample and method}

The Center for European Economic Research, Mannheim, Germany, conducts a quarterly survey among German firms in the field of information and communication about the economic situation (“ZEW Konjunkturumfrage Informationswirtschaft”). Each wave has recurring questions and a section dedicated to varying topics. In Q3 / 2015, the survey featured a number of questions about digital design rights, shown in Table 3 (translated from German). 
Table 3: Survey questions relating to digital design rights

\begin{tabular}{|c|c|}
\hline Question & Type of answer \\
\hline To what extent is your company using own digital designs? & $\begin{array}{l}5 \text { point scale, "not at all” to } \\
\text { "to a large extent" }\end{array}$ \\
\hline \multicolumn{2}{|c|}{$\begin{array}{l}\text { Which legal instruments for protecting digital designs is your company using currently, or has used since } \\
\text { 2013? }\end{array}$} \\
\hline \multicolumn{2}{|l|}{ Registered design rights } \\
\hline \multicolumn{2}{|l|}{ Unregistered design rights } \\
\hline \multicolumn{2}{|r|}{$\begin{array}{l}5 \text { point scale, “never” to } \\
\text { "very frequently" }\end{array}$} \\
\hline \multicolumn{2}{|l|}{ Trademarks } \\
\hline \multicolumn{2}{|l|}{ Unfair competition law } \\
\hline $\begin{array}{l}\text { How would you assess the importance of your company’s digital design } \\
\text { rights for company success? }\end{array}$ & $\begin{array}{l}5 \text { point scale, "completely } \\
\text { unimportant" to “very important” }\end{array}$ \\
\hline \multicolumn{2}{|c|}{ In your opinion, which reasons speak against using digital design rights in your company? } \\
\hline \multicolumn{2}{|c|}{ We are not using digital designs } \\
\hline \multicolumn{2}{|l|}{ Our digital designs are not being copied } \\
\hline \multicolumn{2}{|l|}{ Copies do not affect our company’s performance } \\
\hline We did not think of it & yes / no \\
\hline \multicolumn{2}{|l|}{ We lack the legal expertise } \\
\hline \multicolumn{2}{|l|}{ The available protection is insufficient } \\
\hline \multicolumn{2}{|l|}{ Design rights are difficult to enforce } \\
\hline Design rights are too expensive & \\
\hline
\end{tabular}

The survey was sent out in early September 2015 to a sample of approximately 4000 firms, with a reminder being sent after two weeks. In total, 930 usable questionnaires were returned, yielding a response rate of approximately $23 \%$.

\subsection{Results}

All results relate to firms with five or more employees. Figure 2 shows to what extent firms in information-related industries use own digital designs. The media industry is leading, with nearly $80 \%$ of respondents using digital designs at least to some extent, and $23 \%$ using them to a large extent. Following are, in this order, ICT services (including software), ICT hardware, and knowledge intensive services, The latter two are rather similar in their use of own digital designs, while the first resembles the Media industry. 
Figure 2: Use of own digital designs by firms in information-related industries $(\mathrm{N}=911)$

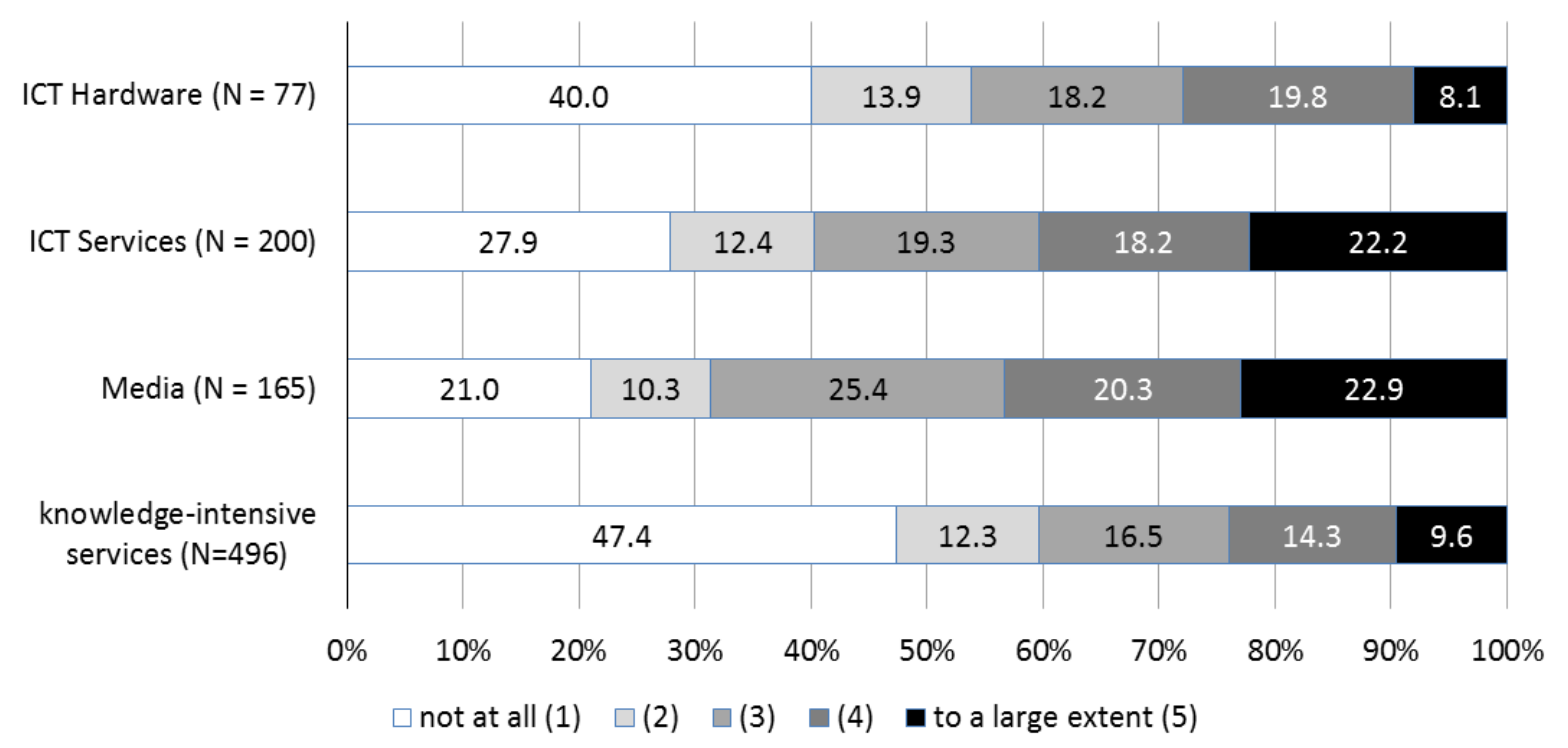

Source: ZEW Konjunkturumfrage Informationswirtschaft, Q3/2015.

For those firms that indicated at least some use of own digital designs, we asked about which means of legal protection they employed. Each of the five means we offered was used at all only by about half of the respondents (see Figure 3). For the respective other half, we find a somewhat heavier use of copyright and trademarks to achieve legal design protection; less use of design rights, registered or unregistered; and little use of unfair competition law. The prevalence of copyright and trademarks can likely be attributed to digital design rights being a relatively new tool, as found also in our interviews (see Section 3.2), despite the fact that they are more suitable. Unfair competition law, in turn, is used least frequently probably because it is harder to apply, relating not directly to the similarity of designs but to the level of fairness of competition.

The share of respondents that use none of the five legal mechanisms for design protection that we offered is about $20 \%$. Thus, a significant majority of about $80 \%$ of respondents uses at least one of these mechanisms to protect their own digital designs. 


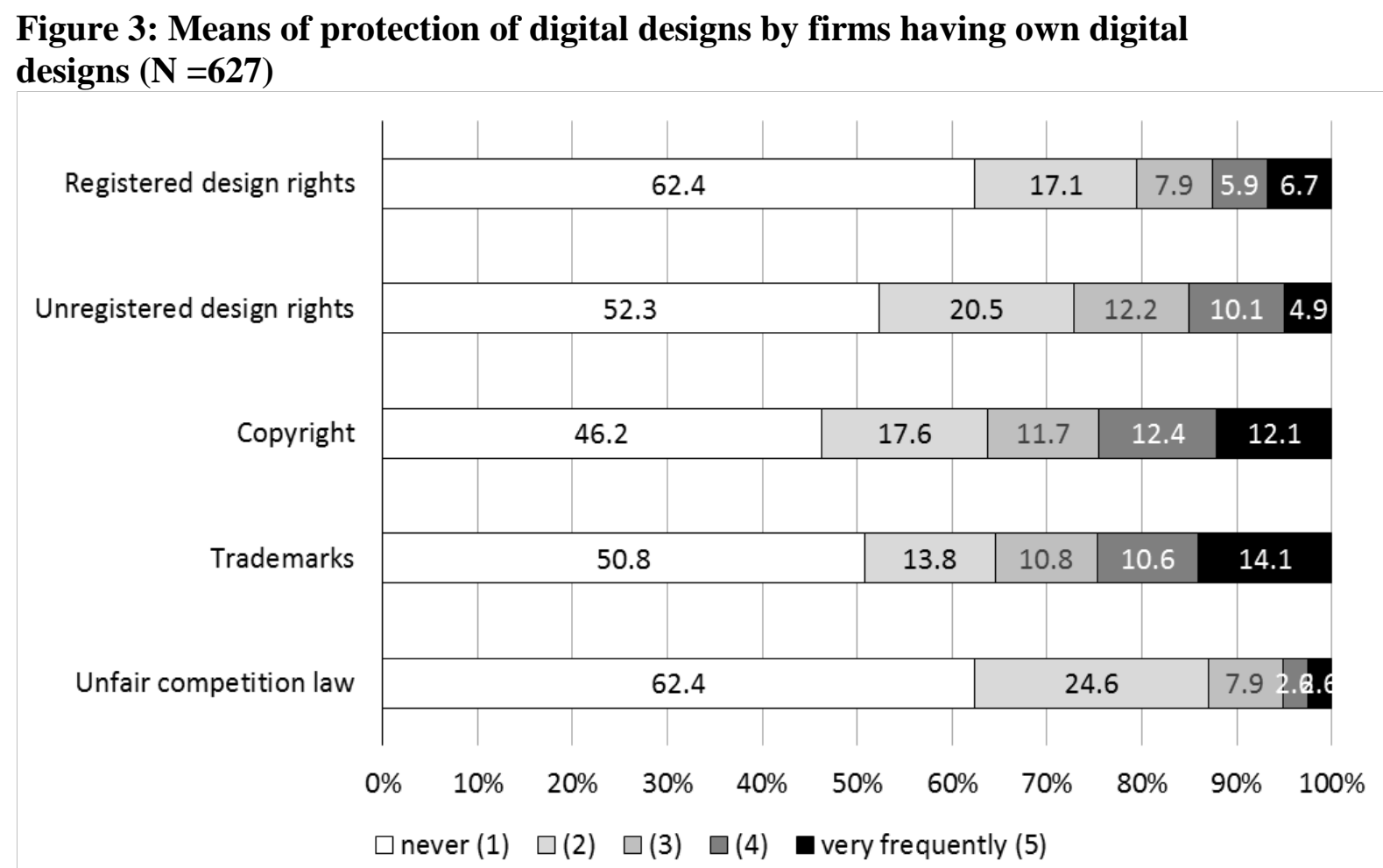

Source: ZEW Konjunkturumfrage Informationswirtschaft, Q3/2015.

To understand the relatively low extent to which digital design rights are used, we asked survey participants which reasons would speak, in their point of view, against the use of digital design rights. The most important reason, ticked by $60 \%$ of respondents, turns out to be that such protection is not needed since copies, to the extent that they occur, do not harm the firm's business (see Figure 4). A further 49\% state that their digital designs are not being copied. These reasons are good news for policy makers.

However, $50 \%$ agree to each of the statements that digital design rights are difficult to enforce and, respectively, too expensive; furthermore, $28 \%$ find the protection achievable with digital design rights insufficient. Summarizing, a considerable share of our respondents perceives the cost-benefit ratio of digital design rights as unfavorable. 
Figure 4: Prevalence of various reasons against the use of digital design rights $(N=604)$

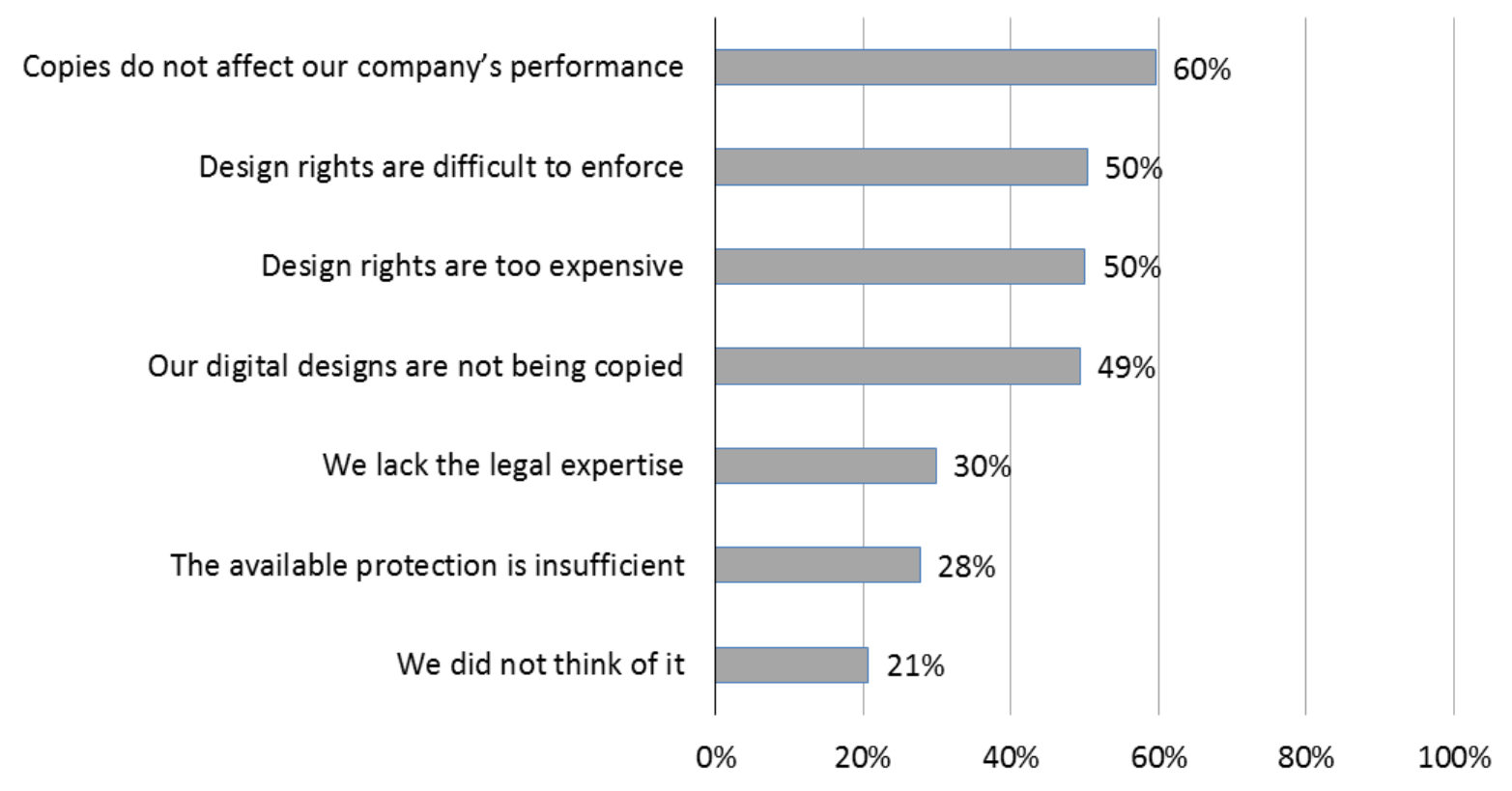

Source: ZEW Konjunkturumfrage Informationswirtschaft, Q3/2015.

\section{Conclusions}

With information and communication technologies becoming ever more pervasive, the importance of digital designs is increasing. Such digital designs, just like other designs and intangible goods more generally, will often need protection against imitation. It is not obvious, however, how effective the various kinds of protection mechanisms are, how broadly firms make use of them, and why they prefer one or the other. To develop well-founded policy recommendations in this regard, we need empirical information about firms' use of digital designs and related protection mechanisms.

The present report provides such information, based on an analysis of Registered Community Designs (RCD) registrations, interviews with legal experts and firm representatives, and a survey of firms in the German ICT industry with more than 900 responses.

Key findings are the following. Registration of RCDs in Class 14.04, which is the applicable category for digital designs, have grown significantly from less than 500 in 2004 to more than 2,500 in 2013. The largest share (36\%) of these RCDs cover "graphical user interfaces”, followed by “icons” (27\%). In terms of country of origin, applicants based in the U.S. constitute the largest group with about one third of all filings. The most prolific EU-users 
are Germany and the UK with shares of $19 \%$ and, respectively, $6 \%$ of registrations. Regarding firms, the distribution of RCDs is highly skewed, with a small number of large software, consumer electronics, and telecom companies accounting for most registrations. Microsoft leads, with Apple and Samsung each registering about half of Microsoft's number.

We found that RCDs have various advantages, at least for heavy users, over alternative protection mechanisms such as copyright and trademarks. Informants representing heavy registrants felt confident about the validity and scope of protection of their digital design registrations. The majority of firms, however, are more hesitant because of the perceived uncertainty surrounding the validity and enforceability of RCDs, and the significant legal expertise and financial resources required to establish thorough protection for digital designs.

Two specific barriers to the registration of digital designs are worth emphasizing. First, they are often animated, and interviewees criticized that transient or moving elements are difficult to capture by a maximum of seven static views as required by the registration system. Second, the enforceability of RCDs for digital designs, in particular through border seizure, is problematic since electronic devices are generally imported "offline”, such that infringement is difficult to observe. Future revisions of legal rules and procedures should address these idiosyncrasies of digital designs.

The survey confirmed findings from our interviews, while also adding new insights. For those firms that indicated at least some use of own digital designs, we find a somewhat heavier use of copyright and trademarks than of design rights, registered or unregistered. The most important reason not to use digital design protection, ticked by $60 \%$ of respondents, turns out to be that such protection is not needed since there is no perceived harm from copies. However, half of respondents agree to each of the statements that digital design rights are difficult to enforce and, respectively, too expensive; furthermore, $28 \%$ find it insufficient. These findings confirm what we learned from interviewees.

Summarizing, digital designs are increasingly used, and firms are in the process of adopting legal protection mechanisms for their digital designs. Policy makers should facilitate an adequate use of such mechanisms through appropriate rules and procedures, while at the same time maintaining a balance between design protection and design freedom. As for other property rights, both an abuse of the system by heavy registrants, possibly resulting in "design thickets”, and the theft of design ideas through imitation must be prevented in order to promote design innovation. 


\section{References}

Du Mont, J.J., Janis, M.D., 2012. Functionality in Design Protection Systems. Journal of Intellectual Property Law 19 (2), 261.

Du Mont, J.J., Janis, M.D., 2014. Virtual Designs. Stanford Technology Law Review 17, 107-181.

Filitz, R., Henkel, J., Tether, B.S., 2015. Protecting aesthetic innovations? An exploration of the use of registered community designs. Research Policy 44 (6), 1192-1206.

Gausling, T., 2014. German Federal Supreme Court expands design protection: 'Birthday Train'. Journal of Intellectual Property Law \& Practice 9 (7), 549-550.

Gutiérrez, H.E., 2012. Advancing with the Times: Industrial Design Protection in the Era of Virtual Migration. IP Theory 3 (1), 1-5.

Kur, A., 2003. Protection of Graphical User Interfaces Under European Design Legislation. International Review of Intellectual Property and Competition Law 34 (1), 50-62.

Miles, M.B., Huberman, A.M., 1994. Qualitative data analysis: an expanded sourcebook (2nd ed.). Sage Publications, Thousand Oaks, CA.

Risch, M., 2014. Functionality and Graphical User Interface Design Patents. Stanford Technology Law Review 17, 53-105.

Rubin, H., Rubin, I., 2005. Qualitative interviewing: the art of hearing data. Sage Publications, Thousand Oaks, CA.

Schickl, L., 2013. Protection of Industrial Design in the United States and in the EU: Different Concepts or Different Labels? The Journal of World Intellectual Property 16 (12), 15-38.

Stigler, R., 2014. Ooey GUI: The Messy Protection of Graphical User Interfaces. Northwestern Journal of Technology and Intellectual Property 12 (3), 215-251. 